\title{
Randomized, double-blind, placebo-controlled study of the analgesic effect of intraoperative esmolol for laparoscopic gastroplasty ${ }^{1}$
}

\author{
Vinicius Barros Duarte de Morais' (D) , Rioko Kimiko Sakata" (D) ,Ana Paula Santana Huang'II' (D) , Leonardo \\ Henrique da Cunha Ferraro'v iD \\ ' MD, Pain Sector, Department of Surgery, Universidade Federal de São Paulo (UNIFESP), Brazil, Design of the \\ study, acquisition of data, final approval. \\ "PhD, Pain Sector, Department of Surgery, UNIFESP, Sao Paulo-SP, Brazil, Design of the study, manuscript \\ writing, critical revision, final approval. \\ "'Master, Pain Sector, Department of Surgery, UNIFESP, Sao Paulo-SP, Brazil. Acquisition of data, final approval. \\ IVPhD, Pain Sector, Department of Surgery, UNIFESP, Sao Paulo-SP, Brazil. Manuscript writing, final approval.
}

\begin{abstract}
Purpose: To evaluate the analgesic effect of esmolol in patients submitted to laparoscopic gastroplasty.

Methods: Forty patients aged between 18 and 50 years with American Society of Anesthesiologists (ASA) physical status scores of II and III who underwent gastric bypass were allocated to two groups. Group 1 patients received a $0.5-\mathrm{mg} / \mathrm{kg}$ bolus of esmolol in $30 \mathrm{~mL}$ of saline before induction of anesthesia, followed by an infusion at $15 \mu \mathrm{g} / \mathrm{kg} / \mathrm{min}$ until the end of surgery. Group 2 patients received $30 \mathrm{~mL}$ of saline as a bolus and then an infusion of saline. Anesthesia included fentanyl $(3 \mu \mathrm{g} / \mathrm{kg})$, propofol $(2-4 \mathrm{mg} / \mathrm{kg})$, rocuronium $(0.6 \mathrm{mg} / \mathrm{kg})$, and $2 \%$ sevoflurane, with remifentanil if necessary. The following parameters were evaluated: pain intensity over $24 \mathrm{~h}$, remifentanil consumption, the first analgesic request, morphine consumption, and side effects.

Results: Pain intensity was lower in the esmolol group except at T0 (after extubation) and $12 \mathrm{~h}$ postoperatively. Remifentanil supplementation, recovery time, and postoperative morphine supplementation were lower in the esmolol group. No differences in the time to the first analgesic request or side effects were found between the groups.

Conclusion: Intraoperative esmolol promotes reductions in pain intensity and the need for analgesic supplementation without adverse effects, thus representing an effective drug for multimodal analgesia in gastroplasty.
\end{abstract}

Key words: Esmolol. Analgesia. Intraoperative Period. Gastroplasty. 


\section{- Introduction}

Postoperative analgesia and recovery of patients undergoing bariatric surgery are challenging. Opioids are effective in relieving postoperative pain; however, especially in morbidly obese, these drugs are associated to side effects ${ }^{1,2}$. Other drugs are often given to increase the analgesic effect of opioids and decrease the incidence and severity of side effects. Also, lower halflife drugs are recommended for these patients ${ }^{1}$. Thus, multimodal analgesia with drugs of different actions is the most prudent approach for morbidly obese patients. A combination of short-acting drugs with a focus on opioid reduction can reduce vomiting and pulmonary complications, enabling early ambulation and shortening the hospital stay ${ }^{3}$.

Beta-adrenergic antagonists, such as esmolol, have been used in some studies for postoperative multimodal analgesiaa,4. Several mechanisms have been proposed for the analgesic action of betablockers such as: modulation of calcium and potassium channels and adrenergic activity, inhibition of sodium channels and facilitation of inhibitory neurotransmitter release $^{3,5,6}$. Esmolol may have analgesic effects, blocking tetrodotoxin-resistant sodium channel activity as lidocaine, in dorsal root ganglion neurons ${ }^{7}$. Facilitation of inhibitory transmitter release, through a mechanism involving Ca2+-entry but in a $\beta 1$-adrenoceptorindependent manner is another mechanism of the antinociceptive effect of esmolol ${ }^{5}$.

The analgesic effect of esmolol is controversial. In some studies, there was a reduction in postoperative opioid consumption ${ }^{3,8,9}$ and pain intensity ${ }^{10}$; however, in other study, esmolol failed to promote an analgesic effect ${ }^{11}$.

The primary objective of this study was to evaluate the effect of esmolol infusion on pain intensity after gastroplasty. The secondary objective was to assess the remifentanil and morphine consumption, the time to require analgesic, and the incidence of side effects. The hypothesis of the study is that esmolol promotes a decrease in pain intensity and in the total opioid consumption.

\section{- Methods}

The study was prospective, randomized, comparative, double-blind, and paired sample. The sample size was calculated using the SPSS $17^{\circ}$ software. The test of choice was Student's t for two independent paired sample with $80 \%$ for power and alpha at $5 \%$. To calculate the sample, it was set 2.4 point for the pain score for the difference between the groups. The result was 19 participants in each group, and it was allocated 20 in each group.

The study was registered at the Brazilian Clinical Trials Registry (ReBec-9w3k77). The data were collected at IGESP Hospital, São Paulo, Brazil.

After approval from the Ethics Committee (CAAE $N^{\circ}$ 83115117.5.0000.5450) and signing the Consent Form, 40 patients with 18 to 50 years old, of both genders, physical status II or III by American Society of Anesthesiology (ASA), submitted to laparoscopic bypass gastroplasty were included in the study. This study was conducted in accordance with the Declaration of Helsinki. Patients with drug allergy; respiratory, renal, hepatic, cardiovascular or psychiatric disease; cognitive alteration; use of beta-adrenergic antagonists; or use of illicit drugs, were excluded.

Participants were randomly drawn and allocated to one of the groups. The randomization was performed by the Randomizer ${ }^{\circledR}$ program. The drawings for allocation in the groups were made by numbers placed in an envelope. On the day of surgery before the onset of anesthesia, the pharmacist opened the participant's envelope and prepared the solution according to the draw, with esmolol or saline solution. The anesthesiologist and the evaluator did not know which group the participant belonged to until the end of the study. In case of an emergency, the anesthesiologist caring for the patient could break the protocol and see the group assignment.

Participants were allocated into two groups. Group 1 (Esmolol) patients received a $0.5 \mathrm{mg} / \mathrm{kg}$ bolus of esmolol in $30 \mathrm{~mL}$ of saline before induction of anesthesia, followed by infusion of $15 \mu \mathrm{g} / \mathrm{kg} / \mathrm{min}$ until end of surgery; group 2 (Control) patients received a $30 \mathrm{~mL}$ bolus of saline and infusion of saline in the same volume as $\mathrm{G} 1$.

Monitoring was performed with a cardioscope, capnograph, pulse oximeter, noninvasive blood pressure, and neuromuscular blockade device.

Before induction of anesthesia, both groups received $2 \mathrm{~g}$ of dipyrone and $40 \mathrm{mg}$ of parecoxib. Anesthesia was performed with fentanyl (3ug/kg; by real bodyweight), propofol (2-4mg/kg) and rocuronium $(0.6 \mathrm{mg} / \mathrm{kg}$ and as required), 50\% oxygen and $2 \%$ sevoflurane. Neuromuscular block was maintained by train of four (TOF), and a post-tetanus count of II, during the surgery. Remifentanil intraoperatively $(0.05$ to $0.2 \mathrm{ug} / \mathrm{kg} / \mathrm{min})$ was given if the heart rate was greater than $15 \%$ and the systolic blood pressure was greater than $20 \%$ of the baseline values. The baseline heart rate and systolic blood pressure was defined as the mean of the two lowest measurements recorded during the 3- to 5-minute interval prior to anesthetic 
induction. In case of hypotension, defined as systolic blood pressure less than $80 \mathrm{mmHg}$ or mean arterial pressure lower than $60 \mathrm{mmHg}$, a bolus of ephedrine ( $0.5 \mathrm{mg}$ IV) was administered; in case of bradycardia, defined as heart rate $<50$, a bolus of atropine was administered $(0.5 \mathrm{mg})$. Intra-abdominal pressure by pneumoperitoneum was the same $(15 \mathrm{mmHg})$ for all patients. The surgical technique was laparoscopic gastric bypass.

Before extubation, $2 \mathrm{mg} / \mathrm{Kg}$ of sugammadex was administered; with an additional dose $(2 \mathrm{mg} / \mathrm{kg})$, if necessary, until it reached $>90 \%$ TOF. Patients were kept in the recovery unit and received oxygen ( $5 \mathrm{~L} / \mathrm{min})$, until saturation was greater than $92 \%$ in ambient air for 10 min. Side effects and complications were noted. Patients with heart rate $<45 \mathrm{bpm}$ or mean blood pressure $<60$ $\mathrm{mmHg}$ were withdrawn from the study and treated.

Postoperative pain was treated with intravenous morphine (5mg per dose) as required. The following were evaluated: consumption of intra-operative remifentanil; time to first drug requirement; intensity of pain by numerical scale from 0 to 10 after extubation (T0) and 30 minutes, $1 \mathrm{~h}, 2 \mathrm{~h}, 6 \mathrm{~h}, 12 \mathrm{~h}$ and $24 \mathrm{~h}$; morphine dose in 24h; and side effects

The primary outcome was pain intensity reduction. The secondary outcomes were remifentanil requirement, morphine dose, and adverse effects. No change in outcome was made after the trial commenced.

The results were submitted to statistical analysis by SPSS $^{\circ}$ program. Sample normality test was performed using Shapiro -Wilk test. The following tests were used: Wilcoxon for age, weight, height, body mass index, duration of surgery, amount of remifentanil, time to recovery, time to first supplementation of morphine, dose of morphine in $24 \mathrm{~h}$, and pain intensity; chi-square test for number of participants requiring remifentanil and morphine supplementation; and Fisher's test for side effects. The level of statistical significance was $p<0.05$.

\section{- Results}

The CONSORT flowchart is shown in Figure 1. There was no difference in demographic data, duration of surgery and ASA between the groups (Table 1).

Pain intensity was lower over $24 \mathrm{~h}$ in the esmolol group, except at T0 and after $12 \mathrm{~h}$ (Table 2). There was a need for supplementation with postoperative morphine in 17 patients from the esmolol group and 20 from the saline group; the morphine dose over $24 \mathrm{~h}$ was lower in the esmolol group. There was no difference in time to the first supplementation (Table 3). Intraoperative remifentanil supplementation was required in 3 patients in the esmolol group and in 17 in the saline group, and the dose was higher in the saline group. The time to wake up was shorter in the esmolol group. There were no differences in side effects between groups (Table 4).

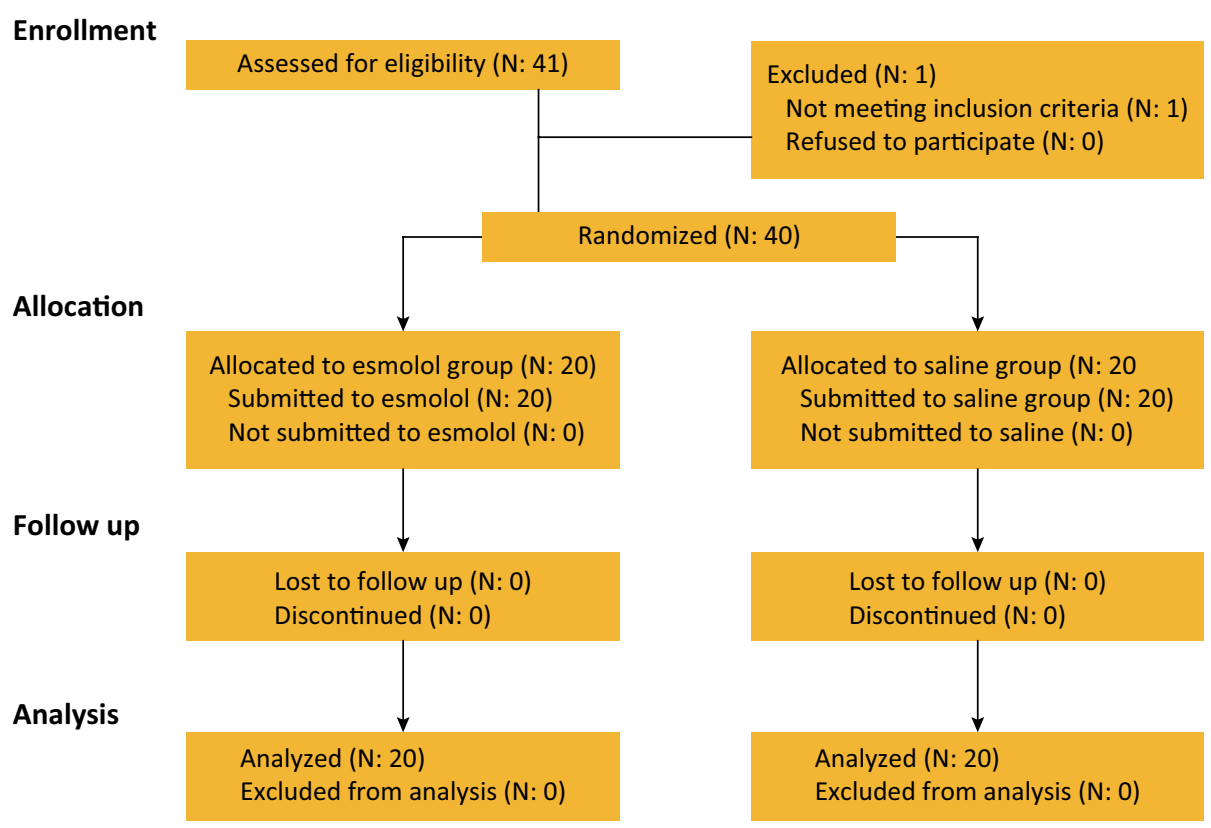

Figure 1 - CONSORT flowchart. 
Table 1 - Characteristics of participants according to age, height, weight, body mass index, duration of surgery (mean \pm SD); gender and ASA physical status (number).

\begin{tabular}{lccc} 
& Esmolol & Saline & P \\
\hline Age (years) & $35.8 \pm 10.9$ & $33.2 \pm 8.7$ & 0.379 \\
Gender: M / F & $3 / 17$ & $3 / 17$ & $\mathrm{NC}$ \\
Weight $(\mathrm{kg})$ & $105.6 \pm 20.2$ & $109.8 \pm 11.2$ & $0.148:$ \\
Height $(\mathrm{cm})$ & $161.9 \pm 8.0$ & $164.4 \pm 9.7$ & 0.456 \\
BMI $\left(\mathrm{kg} . \mathrm{m}^{-2}\right)$ & $40.1 \pm 5.5$ & $40.7 \pm 3.3$ & 0.148 \\
ASA: I / II & $0 / 20$ & $0 / 20$ & $\mathrm{NC}$ \\
Duration of surgery & $104.3 \pm 14.3$ & $112.8 \pm 12.5$ & 0.078 \\
\hline
\end{tabular}

Wilcoxon test; BMI: body mass index; ASA: American Society of Anesthetists; NC: not calculated

Table 2 - Intraoperative supplementation with remifentanil (dose and number of patients needing supplementation), time until recovery, time until first postoperative first supplementation, and morphine (dose in $24 \mathrm{~h}$ and number of patients needing supplementation) (mean \pm SD).

\begin{tabular}{lccc}
\hline & Esmolol & Saline & P \\
\hline $\begin{array}{l}\text { Intraoperative } \\
\text { remifentanil }(\mu \mathrm{g})\end{array}$ & $620.0 \pm 182.5$ & 1058.8 & $0.001^{+}$: \\
$\begin{array}{l}\text { Number who needed } \\
\text { remifentanil }\end{array}$ & 3 & 17 & $0.001^{\ddagger}$ \\
$\begin{array}{l}\text { Time for recovery } \\
\text { (min) }\end{array}$ & $9.0 \pm 3.4$ & $12.5 \pm 3.7$ & $0.006^{+}:$ \\
$\begin{array}{l}\text { First supplementation } \\
\text { (min) }\end{array}$ & $37.1 \pm 16.9$ & $33.0 \pm 19,2$ & $0.535^{+}:$ \\
$\begin{array}{l}\text { Dose of morphine } \\
\text { (mg) }\end{array}$ & $7.0 \pm 4.4$ & $13.0 \pm 5.7$ & $0.002^{+}:$ \\
$\begin{array}{l}\text { Number who used } \\
\text { morphine }\end{array}$ & 17 & 20 & $0.100^{\ddagger}$ \\
\hline
\end{tabular}

${ }^{+}$: Wilcoxon test; ${ }^{\ddagger}$ : qui-square; SD: standard deviation

Table 3 - Intensity of pain at recovery (TO), after 30 minutes, 1, 2, 6, 12 and $24 \mathrm{~h}$, according to numerical scale - median (minimum- maximum).

\begin{tabular}{lccc}
\hline & Esmolol & Saline & P \\
\hline T0 & $0(0-8)$ & $0(0-8)$ & 0.180 \\
$30 \mathrm{~min}$ & $5(0-8)$ & $6(2-10)$ & 0.032 \\
$1 \mathrm{~h}$ & $5(0-9)$ & $8(3-10)$ & 0.004 \\
$2 \mathrm{~h}$ & $2(0-6)$ & $5(2-8)$ & 0.002 \\
$6 \mathrm{~h}$ & $3(0-5)$ & $4(1-7)$ & 0.047 \\
$12 \mathrm{~h}$ & $1(0-2)$ & $1(0-3)$ & 0.262 \\
$24 \mathrm{~h}$ & $0(0-2)$ & $1(0-2)$ & 0.029 \\
\hline
\end{tabular}

Wilcoxon test; $\mathrm{TO}=$ at recovery of consciousness
Table 4 - Side effects - number (\%).

\begin{tabular}{lccc}
\hline & Esmolol & Saline & P \\
\hline Nausea & $6(30 \%)$ & $9(45 \%)$ & 0.515 \\
Vomiting & $0(0 \%)$ & $0(0 \%)$ & NC \\
Somnolence & $9(45 \%)$ & $7(35 \%)$ & 1.000 \\
Hypotension & $3(15 \%)$ & $3(15 \%)$ & 1.000 \\
Bradycardia & $2(10 \%)$ & $2(10 \%)$ & 1.000 \\
Bronchospasm & $0(0 \%)$ & $1(5 \%)$ & 1.000 \\
\hline
\end{tabular}

Fisher test; NC: not calculated

\section{- Discussion}

We found that intraoperative continuous infusion of esmolol reduce pain intensity in the first $24 \mathrm{~h}$, the morphine dose over $24 \mathrm{~h}$ and the amount of remifentanil use during bypass laparoscopic gastroplasty. These results indicated that esmolol may be used effectively to achieve an opioid-sparing effect during surgery and qualitatively better recovery from anesthesia.

Inadequate control of postoperative pain is a common cause of prolonged hospital stay ${ }^{12}$. In this study, analgesia was improved with esmolol, both during surgery and in the postoperative period over 24 hours. This result is similar to literature on other types of surgeries and patients with BMI within the normal range $\mathrm{r}^{8,9,13}$.

In one study, with a similar dose of esmolol as in this study, it was observed reduction of alfentanil infused during laparoscopic cholecystectomy, and also the dose of tramadol and diclofenac for postoperative pain control ${ }^{14}$.

In hysterectomy, esmolol infusion in non-obese patients, it was a reduced dose of remifentanil, and the postoperative analgesic consumption was lower in the esmolol group. Like our study the nausea and vomit are the same in each group ${ }^{15}$.

Intravenous infusion of esmolol reduced the intraoperative and postoperative analgesic consumption, reduced visual analogue scale scores in the early postoperative period and prolonged the time to first analgesia, in patients undergoing septorhinoplasty ${ }^{10}$.

Remifentanil was used for intraoperative supplementation because although it is liposoluble, its degradation is rapid, and does not enter the lipophilic compartment. It is used safely in obese patients, with the volume of distribution and clearance being similar to that of the non-obese population ${ }^{16}$. Reduction in remifentanil consumption in the esmolol group may have led to lower pain scores because this opioid may cause hyperalgesia ${ }^{17}$. 
Intraoperative esmolol may reduce the consumption of opioids and their side effects, such as nausea, vomiting and ileus, with less time to hospital discharge. In this study, a $0.5 \mathrm{mg} / \mathrm{kg}$ bolus was given, similar to the majority of literature reports ${ }^{3,10,15}$. The infusion was performed at lower doses than those in the literature for nonobese which include reports of $5 \mu \mathrm{g} / \mathrm{kg} / \mathrm{min}$ ${ }^{10}, 10 \mu \mathrm{g} / \mathrm{kg} / \mathrm{min}^{8}, 30 \mu \mathrm{g} / \mathrm{kg} / \mathrm{min}^{15}, 50 \mathrm{ug} / \mathrm{kg} / \mathrm{min}^{3,18}$. There are no pharmacokinetic models to morbidly obese population, so in our study we use a low dose of fentanyl.

Esmolol was hemodynamically safe, and there were no differences in the incidence of bradycardia or hypotension between the groups, as in the studies of the literature ${ }^{8,9-11,15,18}$. In this study, esmolol was not associated with significant bradycardia. Hypotension was related to boluses greater than $0.5 \mathrm{mg}$ in one review $^{19}$. In one study in the esmolol group, the heart rate was slightly higher than that in the placebo group 10. In another study, more bradycardia was observed with esmolol but without hemodynamic instability ${ }^{19}$. Other studies have demonstrated hemodynamic benefits for orotracheal intubation ${ }^{20}$ and reduced myocardial oxygen consumption by preventing adverse events during surgery ${ }^{21}$.

There was no significant difference in the incidence of nausea and vomiting, unlike in previous studies $^{14,22}$, but nausea was less common in the esmolol group. However, a preventive antiemetic drug was administered in this study for both groups. Prevention of postoperative nausea and vomiting is very important, especially after gastroplasty. Due to the high incidence of nausea and vomiting in this type of surgery it is not possible to keep them without prophylactic antiemetic. There was one case of bronchospasm, but with no correlation with esmolol, as it was observed in the saline group.

\section{- Limitations}

Reduced incidence of nausea and vomiting by the administration of prophylactic antiemetic may have influenced the absence of difference in these adverse effects.

\section{- Conclusion}

Intraoperative esmolol promotes reduction in pain intensity, and need for supplementation, without increased risks and represents an effective drug for multimodal analgesia in obese patients submitted to gastroplasty.

\section{- References}

1. Chung SA, Yuan H, Chung F. A systemic review of obstructive sleep apnea and its implications for anesthesiologists. Anesth Analg. 2008;107(5):1543-6. doi: 10.1213/ ane.0b013e318187c83a.

2. Wheeler M, Oderda GM, Ashburn MA, Lipman A G. Adverse events associated with post-operative opioid analgesia: a systematic review. J Pain. 2002;3(3):159-80. doi: 10.1054/jpai.2002.123652.

3. Chia YY, Chan MH, Ko NH, Liu K. Role of beta-blockade in anesthesia and postoperative pain management after hysterectomy. Br J Anaesth. 2004;93(6):799-805. doi: 10.1093/bja/aeh268.

4. Collard V, Mistraletti G, Taqi A, Asenjo JF, Feldman LS, Fried GM, Carli F. Intraoperative esmolol infusion in the absence of opioids spares postoperative fentanyl in patients undergoing ambulatory laparoscopic cholecystectomy. Anesth Analg. 2007;105(5):1255-62. doi: 10.1213/01. ane.0000282822.07437.02.

5. Yasui $Y$, Masaki E, Kato F. Esmolol modulates inhibitory neurotransmission in the substantia gelatinosa of the spinal trigeminal nucleus of the rat. BMC Anesthesiol. 2011;5(11):15. doi: 10.1186/1471-2253-11-15.

6. Pertovaara $A$. The noradrenergic pain regulation system: a potential target for pain therapy. Eur J Pharmacol. 2013;716(1-3):2-7 . doi: 10.1016/j.ejphar.2013.01.067.

7. Tanahashi S, lida H, Dohi S, Oda A, Osawa Y, Yamaguchi S. Comparative effects of ultra-short-acting beta1-blockers on voltage-gated tetrodotoxin-resistant $\mathrm{Na}+$ channels in rat sensory neurons. Eur J Anaesthesiol. 2009;26(3):196200. doi: 10.1097/EJA.0b013e32831ac268.

8. Lee MH, Chung MH, Han CS, Lee JH, Choi YR, Choi EM, Lim HK, Cha YD. Comparison of effects of intraoperative esmolol and ketamine infusion on acute postoperative after remifentanil-based anesthesia in patients undergoing laparoscopic cholecystectomy. Korean J Anesthesiol. 2014;66(3):222-9. doi: 10.4097/kjae.2014.66.3.222.

9. López-Álvarez S, Mayo-Moldes $M$, Zaballos $M$, Iglesias BG, Blanco-Dávila R. Esmolol versus ketamineremifentanil combination for early postoperative analgesia after laparoscopic cholecystectomy. Can J Anaesth. 2012;59(5):442-8. doi: 10.1007/s12630-012-9684-x.

10. N, Cizmeci EA, Canbay O. Intraoperative esmolol infusion reduces postoperative analgesic consumption and anaesthetic use during septorhinoplasty: a randomized trial. Rev Bras Anestesiol. 2014;64(5):343-9. doi: 10.1016/j.bjan.2013.10.013.

11. Coloma M, Chiu JW, White PF, Armbruster SC. The use of esmolol as an alternative to remifentanil during desflurane anesthesia for fast-track outpatient gynecologic laparoscopic surgery. Anesth Analg. 2001;92(2):352-7. doi: 10.1097/00000539-200102000-00014.

12. Cooke FE, Samuels JD, Pomp A, Gadalla F, Wu X, Afaneh C, Gregory F Goldstein DA. Randomized, double-blind, placebo-controlled trial of intravenous acetaminophen on hospital length of stay in obese individuals undergoing sleeve gastrectomy. Obes Surg. 2018;28:2998-3006. doi: 10.1007/s11695-018-3316-7. 
13. Watts $R$, Thiruvenkatarajan V, Calvert $M$, Newcombe $G$, van Wijk RM. The effect of peri-operative esmolol on early postoperative pain: A systematic review and metaanalysis. J Anaesthesiol Clin Pharmacol. 2017;33:28-39. doi: 10.4103/0970-9185.202182.

14. Ozturk T, Kaya H, Aran G, Aksum M, Savacu S. Postoperative beneficial effects of esmolol in treated hypertensive patients undergoing laparoscopic cholecystectomy. $\mathrm{Br} \mathrm{J}$ Anaesth. 2008;100(2):211-4. doi: 10.1093/bja/aem333.

15. Hwang WJ, Moon YE, Cho SJ, Lee J. The effect of a continuous infusion of low-dose esmolol on the requirement for remifentanil during laparoscopic gynecologic surgery. J Clin Anesth. 2013;25(1):36-41. doi: 10.1016/j.jclinane.2012.06.005.

16. Santonocito C, Noto A, Crimi C, Sanfilippo F. Remifentanilinduced postoperative hyper-algesia: current perspectives on mechanisms and therapeutic strategies. Local Reg Anesth. 2018;11:15-23. doi: 10.2147/LRA.S143618.

17. Leal PC, Salomão R, Brunialti MK, Sakata RK. Evaluation of the effect of ketamine on remifentanil-induced hyperalgesia: a double-blind, randomized study. J Clin Anesth. 2015;27(4):331-7. doi: 10.1016/j.jclinane.2015.02.002.

18. Yu SK, Tait G, Karkouti K, Wijeysundera D, McCluskey $S$, Beattie WS. The safety of perioperative esmolol: a systematic review and meta-analysis of randomized controlled trials. Anesth Analg. 2011;112(2):267-81. doi: 10.1213/ANE.0b013e3182025af7.

19. Dereli N, Tutal ZB, Babayigit M, Kurtay A, Sahap M, Horasanli E. Effect of intraoperative esmolol infusion on anesthetic, analgesic requirements and postoperative nauseavomitting in a group of laparoscopic cholecystectomy patients. Rev Bras Anestesiol. 2015;65(2):141-6. doi: 10.1016/j.bjan.2014.08.002.

20. Talwar V, Ganeriwal V, Aggarwal S, Gupta A. Efficacy of combination of esmolol and dil-tiazem for attenuating hemodynamic response to laryngoscopy and intubation: a prospective randomized study. Anesth Essays Res. 2018;12(3):674-9. doi: 10.4103/aer.AER_76_18.

21. Zhang XK, Hu $Q$, Chen $Q H$, Wang $\bar{W} X$. The effect of continuous perfusion of esmolol on cardiovascular risk in elderly patients undergoing noncardiac surgery. Pharmazie. 2017;72(8):487-9. doi: 10.1691/ph.2017.6992.

22. Thiruvenkatarajan V, Watts $R$, Calvert M, Newcombe G, Van Wijk RM. The effect of esmolol compared to opioids on postoperative nausea and vomiting, postanesthesia care unit discharge time, and analgesia in noncardiac surgery: a meta-analysis. J Anaesth Clin Pharmacol. 2017;33(2):17280. doi: 10.4103/0970-9185.209747.

\section{Correspondence:}

Rioko Kimiko Sakata

Rua Três de Maio, 61/51

04044-020 São Paulo - SP Brasil

Tel.: (55 11)5576 4848

rsakata@unifesp.br

Received: Dec 17, 2019

Review: Feb 13, 2020

Accepted: Mar 15, 2020

\author{
Conflict of interest: none \\ Financial source: CAPES (Finance Code 001)
}

\begin{abstract}
${ }^{1}$ Research performed at Instituto de Gastroenterologia, Sao Paulo-SP, Brazil. Part of Master degree thesis, Interdisciplinary Surgical Science Postgraduate Program, Department of Surgery, UNIFESP. Tutor: Rioko Kimiko Sakata.
\end{abstract}

This is an Open Access article distributed under the terms of the Creative Commons Attribution License, which permits unrestricted use, distribution and reproduction in any medium, provided the original work is properly cited. 